\title{
Strategies for How Men Can Advance Gender Equity in Political Science
}

\section{INTRODUCTION: STRATEGIES FOR HOW MEN CAN ADVANCE GENDER EQUITY IN POLITICAL SCIENCE}

\author{
Daniel J. Mallinson, Pennsylvania State University, Harrisburg \\ Rebecca D. Gill, University of Nevada, Las Vegas
}

\section{DOI:10.1017/S1049096521000202}

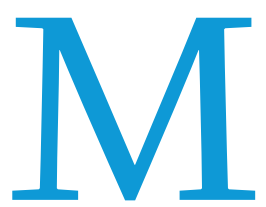
uch has been written about gender inequalities in political science (Argyle and Mendelberg 2020; Goodman and Pepinsky 2019; Kittilson 2015; Palmer, van Assendelft, and Stegmaier 2020). Additionally, the COVID-19 pandemic is exacerbating gender inequalities in academia (Myers et al. 2020; Yildirim and Eslen-Ziya 2020). However, much of the advice proffered for addressing gender equity in the profession has been targeted at women (to help them "fit in" to male-dominant work environments) or professional bodies (e.g., reducing "manels") (Bodkin and Fleming 2019; O'Brien 2020; Windsor and Crawford 2020). This spotlight directly addresses men in the discipline about their role in promoting gender equity. Doing so shifts the burden off women colleagues and invites men to share the burden of changing macro-, meso-, and micro-level structures and barriers to equity. As Perry and Gibson (2020) argued, "those with the most power have the greatest responsibility to change systems that are unequal."

The spotlight stems from the APSA 2018 Hackathon (Htun 2019). One group was tasked with developing strategies for how men could advance women's equality in political science. This is an aim that we tried to broaden to gender equity, althoughadmittedly-much of our spotlight's advice remains focused on women.

The Hackathon produced recommendations (see https:// tinyurl.com/apsa-hackathon-what) in the following areas:

- advocacy and recognizing achievements

- inclusive networks

- women as journal editors and in positions of power

- standing up

- respecting and knowing gender research and diversifying syllabi

- building better systems

- checking privilege and biases

- improving hiring systems

- avoiding manels and modeling behavior

- improving transparency

The articles in this spotlight build on this work by delving more deeply into each topic. The collection demonstrates how crucial men are in advancing gender equity in the discipline. Each article provides actionable advice for men and is targeted largely at individuals and departments. This was a conscious choice on our part; it is in these everyday settings that men must serve as allies for their female and nonbinary colleagues. Our hope is that this spotlight calls further attention to these issues and provides a starting point for those who want to contribute positively to the creation of an equitable discipline.

For our purposes, an ally is a member of a privileged social group who works to end the oppression of those not in the privileged social group (Washington and Evans 1991). ${ }^{1}$ First, potential allies need to recognize that there is a problem that should be remedied. In the case of gender-equity allies, this means the need to recognize their own privilege within the system. Along with a personal commitment to fairness, this predicts helpful allyship among members of the privileged in-group (Prime and Moss-Racusin 2009). Second, men who are successful allies for gender equity also must develop an understanding of the gender biases that drive inequities lest their good-faith advocacy unintentionally affirms these stereotypes (Anicha, Bilen-Green, and Green 2020).

Our authors address most dimensions of allyship identified by the 2018 Hackathon. Each article interweaves personal experience and social science to illustrate the role of men in improving gender equity. Leah C. Windsor and Cameron G. Theis leverage their mentorship relationship to discuss systemic and individual mentorship of women political scientists. They speak particularly to men in the middle of their career-the crucial "fulcrum" between an often-precarious junior status and becoming part of the "old guard." Rebecca A. Reid addresses the "leaky pipeline," particularly the disproportionate uncredited service work of nonwhite, non-male faculty. She points out that men must invest in supporting women even if it brings them no prestige or reward and when it is difficult and inconvenient. Emily M. Farris, Andrea Malji, and Julia Marin Hellwege address how men can provide allyship in research, teaching, and service for junior scholars establishing their career, another leaky section of the academic pipeline. Anisha C. Datta and David A. Siegel discuss the lack of inclusiveness in professional networks and how traditional networking methods (e.g., "happy hours") do not increase inclusivity. They suggest greater mindfulness in diversifying professional networks. Leah C. Windsor, Kerry F. Crawford, and Marjike Breuning address MENtorship through the lens of a hidden game of chutes and ladders. They argue for equitable family-leave policies and mentoring programs to help underrepresented groups more successfully navigate these unwritten professional rules.

Tarah Williams, Paul F. Testa, Kylee Britzman, and Matthew V. Hibbing demonstrate that men are more responsive to messaging from other men about the \#MeToo movement. This has implications for the transmission of pro-equity messaging in the discipline. Men must engage other men instead of expecting their 
underrepresented colleagues to do the work. Tina Zappile calls for men to "stand up" for women in groups. There are many formal and informal groups in academic life, and she discusses how men can ensure that women are not excluded from the benefits of these groups. Based on Black and Latina feminist literature as well as his
Myers, Kyle R., Wei Yang Tham, Yian Yin, Nina Cohodes, Jerry G. Thursby, Marie C. Thursby, Peter Schiffer, Joseph T. Walsh, Karim R. Lakhani, and Dashun Wang. 2020. "Unequal Effects of the COVID-19 Pandemic on Scientists." Nature Human Behaviour 4 (9): 88o-83.

O’Brien, Diana Z. 2020. "Navigating Political Science as a Woman." PS: Political Science \& Politics 53 (2): 315-17.

\section{This spotlight directly addresses men in the discipline about their role in promoting gender equity.}

personal experience, Guillermo Caballero presents a framework for men to understand their actions and change problematic behavior. Elizabeth Carlson and Christopher Zorn share their experience in developing search-committee processes aimed at mitigating implicit bias in letters of recommendation for new faculty hires. As they explain, this has increased the number of women candidates interviewed and hired. Finally, Patricia A. Stapleton and Melissa R. Michelson offer insights gained from the \#MeTooPoliSci collective and APSA's survey of women in the profession. In addition to corroborating the disproportionate service burden and negative bias in student evaluations of teaching, they offer practical methods for men to ally with their women colleagues.

We also recognize the diverse scholars that reviewed the spotlight articles: Lisa Argyle, Victor Asal, Marijke Breuning, Paul Collins, Kerry Crawford, Emily Farris, Julia Marin Hellwege, Mirya Holman, Matt Lebo, Melissa Michelson, Sarah McLaughlin Mitchell, Rebecca Reid, David Siegel, Cameron Thies, John Tuman, Lee Walker, Tarah Williams, Anne M. Whitesell, Leah Windsor, and Kim Yi Dionne. This entire spotlight is a collective effort of the writers, editors, and reviewers, and it is intended to capture the diversity of our discipline and to engage mid- and early-career men in allyship.

\section{NOTE}

1. We are sensitive to the potential downside of using the "allyship" label to describe men's work in promoting gender equity. For a helpful review of these issues, see Carlson et al. (2020). However, given the centrality of the term in the 2018 Hackathon's discourse and the need to utilize commonly understood language for this concept, we opt to use the term.

\section{REFERENCES}

Anicha, Cali L., Canan Bilen-Green, and Roger Green. 2020. "A Policy Paradox: Why Gender Equity Is Men's Work." Journal of Gender Studies 29 (7): 847-51.

Argyle, Lisa P., and Tali Mendelberg. 2020. "Improving Women's Advancement in Political Science: What We Know About What Works.” PS: Political Science $\mathcal{E}$ Politics 53 (4): 718-22.

Bodkin, Candice Pippin, and Casey J. Fleming. 2019. "Supporting Women Scholars" Paths to Academia: An Examination of Family-Friendly Policies of Public Affairs Doctoral Programs." Journal of Public Affairs Education:1-25. https:// doi.org/10.1080/15236803.2019.1694385

Carlson, Juliana, Cliff Leek, Erin Casey, Rich Tolman, and Christopher Allen. 2020. "What's in a Name? A Synthesis of 'Allyship' Elements from Academic and Activist Literature." Journal of Family Violence 35 (8): 889-98.

Goodman, Sara Wallace, and Thomas B. Pepinsky. 2019. "Gender Representation and Strategies for Panel Diversity: Lessons from the APSA Annual Meeting." PS: Political Science \& Politics 52 (4): 669-76.

Htun, Mala. 2019. "Promoting Diversity and Inclusion through Engagement: The APSA 2018 Hackathon." PS: Political Science \& Politics 52 (4): 677-83.

Kittilson, Miki Caul. 2015. "Advancing Women in Political Science: Navigating Gendered Structures of Opportunity." PS: Political Science \& Politics 48 (3): 450-53.
Palmer, Barbara, Laura van Assendelft, and Mary Stegmaier. 2020. "Revisiting the Presence of Women in Political Science Journal Editorial Positions." PS: Political Science \& Politics 53 (3): 499-504.

Perry, Kate, and Tobias T. Gibson. 2020. "Not All Mentors.” Inside Higher Ed, July 31. www.insidehighered.com/advice/2020/07/31/advice-successful-malementorships-women-academe-opinion.

Prime, Jeanine, and Corinne A. Moss-Racusin. 2009. Engaging Men in Gender Initiatives: What Change Agents Need to Know. New York: Catalyst Press.

Washington, Jamie, and Nancy J. Evans. 1991. "Becoming an Ally.” In Beyond Tolerance: Gays, Lesbians and Bisexuals on Campus, ed. Nancy J. Evans and Vernon A. Wall, 195-204. Alexandria, VA: American Association for Counseling and Development.

Windsor, Leah C., and Kerry F. Crawford. 2020. "Best Practices for Normalizing Parents in the Academy: Higher- and Lower-Order Processes and Women and Parents' Success." PS: Political Science \& Politics 53 (2): 275-80.

Yildirim, T. Murat, and Hande Eslen-Ziya. 2020. "The Differential Impact of COVID 19 on the Work Conditions of Women and Men Academics During the Lockdown." Gender, Work \& Organization advance online publication.

\section{MENTORSHIP: "MEN IN THE MIDDLE" AND THEIR ROLE AS ALLIES IN ADDRESSING GENDER BIAS}

\section{Leah C. Windsor, The University of Memphis Cameron G. Thies, Arizona State University}

\section{DOI:10.1017/S1049096521000044}

The issue of mentorship for women in political science has gained traction and prominence in recent years. Conceptualized initially as a "leaky pipeline" (Blickenstaff 2005), Crawford and Windsor (2021) suggest that a "chutes and ladders game" is a better metaphor for the twists and turns of academic careers given endogenous bias and exogenous life events. The pioneering leadership of female scholars in the Women's Caucus for Political Science and the Women's Caucus in International Studies, for example, have provided professional support that has helped women to navigate male-dominated academic spaces (Akos and Kretchmar 2016; Claypool et al. 2017; Crawford and Windsor 2019; Hesli, Lee, and Mitchell 2012; Mitchell and Martin 2018; Mitchell, Lange, and Brus 2013). Programs including Visions in Methodology, Journeys in World Politics, and Pay It Forward have continued these efforts, providing best practices for tangible skills such as bargaining and negotiations (Mitchell and Hesli 2013), navigating the job market (Kim and Grofman 2019), achieving balance amid the competing demands of work and family formation (Kim, Fitzsimons, and Kay 2018), and maximizing their research productivity (Hancock, Baum, and Breuning 2013). Led by women for women, these groups have been a necessary first step for validating the legitimate concerns of women in our profession.

Women initially embraced the message of "lean in" promoted by Sandberg (2013) as a call to support one another, but the movement quickly lost favor given its reliance on classism and 